\title{
The characteristics of breast cancer in geriatric patients
}

\author{
Aybala Ağaç Ay ${ }^{1}$, Haluk Ulucanlar ${ }^{2}$, Selçuk Misirligil ${ }^{3}$, Ahmet Alyanak ${ }^{1}$ and Saadet Akturan ${ }^{1 *}$ \\ ${ }^{1}$ General Surgery, Yenimahalle Training and Research Hospital, Yildirim Beyazit University, Turkey \\ ${ }^{2}$ General Surgery, Ankara Oncology Training and Research Hospital, Turkey \\ ${ }^{3}$ Kirikkale University School of Medicine, General Surgery, Turkey
}

\begin{abstract}
Breast cancer is the most commonly seen malignant tumor formation in women all over the world with increasing frequency with age. About $48 \%$ of the breast cancer is seen on patients over 65 and about $30 \%$ of those cases are seen in population over 70.105 patients over 65 who underwent modified radical mastectomy (MRM) for breast cancer were included in the study. In elderly breast cancer patients, primary treatment approach is surgery with no significant difference was found in terms of post-operative complications when compared with younger patient groups. Treatment guidelines follow the path of partial mastectomy with axillary dissection and breast radiotherapy during post-operative term.
\end{abstract}

\section{Introduction}

Breast cancer is the most commonly seen malignant tumor formation in women all over the world with increasing frequency with age. It is a serious public health issue with a $12.3 \%$ lifetime incidence rate in women. According to data from 2011, there are 2.899.726 diagnosed breast cancer patients alone in USA [1]. About $48 \%$ of the breast cancer is seen on patients over 65 and about $30 \%$ of those cases are seen in population over 70 [1]. For this reason, it is crucial to understand the characteristics of breast cancer in elderly patients.

\section{Materials and methods}

105 patients over 65 who underwent modified radical mastectomy (MRM) for breast cancer were included in the study. The patients with comorbid diseases with expected high mortality rates during diagnosis and treatment periods were excluded from the study. Furthermore, patients with no distant metastases, patients without local advanced grade tumors and patients without any issues that might affect surgery were all included in the study.

\section{Results}

105 patients over 65 were included in the study. Mean age of the patients was 68.87 . When patients were grouped according to their tumor grades, $46(43.8 \%)$ of the patients had Grade I, 34 (32.4\%) patients had Grade II, and 25 (23.8\%) patients were diagnosed with Grade III tumors. When pathological types were investigated, 100 (95.2\%) patients had invasive ductal cancer, 4 (3.8\%) patients had invasive lobular cancer and 1 patient was diagnosed with primary breast lymphoma. Out of 105 patients, 20 (19\%) patients had axillary lymph node involvement and other 85 (81\%) patients had no axillary lymph node involvement.

\section{Discussion}

Breast cancer is the most commonly seen malignant tumor formation in women all over the world with increasing frequency with age. It is a serious public health issue with a $12.3 \%$ lifetime incidence rate in women. According to data from 2011, there are 2.899 .726 diagnosed breast cancer patients alone in USA [1]. About $48 \%$ of the breast cancer is seen on patients over 65 and about $30 \%$ of those cases are seen in population over 70 [1]. With the general aging of the world's population, the projected incidence rate and prevalence of breast cancer is thought to increase by $30 \%$ in female population over 65 years of age in the next century [2-4]. The most commonly diagnosed stage of the disease is stage 2 breast cancer; with an increasing rate of stage 3 and 4 breast cancer diagnoses in populations over $75[5,6]$. Despite the difference in staging of the disease, breast cancer in those elderly patients are relatively less aggressive and the breast cancer mortality shows a decrease with age. This lowering rate in elderly breast cancer cases can be explained by the increase in positive hormonal receptors, decreased HER2 ovary expression and difference in biological behavior of the tumors with increased age [2].

Mammograms are used as effective screening tools in females between 50-69 especially after becoming more popular in 1990's in developed countries and as a result, there is a significant decrease in mortality associated with breast cancer. In Netherlands, a project was designed in 1989 for bilateral mammographic examination of females between 50-69 and in 2009, the targeted 1.1 million patients were almost achieved by 900.000 patients screened so far. Although some researchers argue that including groups without apparent breast cancer risk to mammography examinations might cause side effects in the future; mammograms constitute the most commonly used screening method today $[7,8]$.

In elderly breast cancer patients, primary treatment approach is surgery with no significant difference was found in terms of postoperative complications when compared with younger patient groups.

Correspondence to: Saadet Akturan, General Surgery, Yenimahalle Training and Research Hospital, Yildirim Beyazit University, Turkey, Tel: +90 312 5872000; E-mail: akturansaadet@yahoo.com

Key words: breast cancer, elderly, geriatric patients

Received: November 07, 2016; Accepted: November 24, 2016; Published: November 28, 2016 
Treatment guidelines follow the path of partial mastectomy with axillary dissection and breast radiotherapy during post-operative term [9]. In tumors over $1 \mathrm{~cm}$, radiotherapy following partial mastectomy is thought to be very effective. Quite a number of studies showed the significant efficacy of postoperative radiotherapy in blocking local recurrences without affecting mortality $[6,10]$. Many countries employ a radiotherapy protocol of 5-times-a-week with a daily dosage of 1.8-2 Gy every time that adds up to $50 \mathrm{~Gy}$ in total [2]. Ultrasonography plays an important role in imaging studies for breast cancer. Following detection of suspicious lesions in ultrasonography, digital mammography and breast MRI are used for clear assessment of the detected masses. As with breast-sparing surgical approaches today are becoming more widespread, the importance of intraoperative ultrasonography is also increased. Moreover, the fact that the most effective method of measuring breast flap thickness during intraoperative period is ultrasonography makes it crucial that the surgeons should be educated on this subject $[2,11]$.

The fact that a clear treatment protocol is not defined in advanced age breast cancer causes a wide difference in treatment from the planned chemotherapy drugs and dosages to the decision of planning postoperative radiotherapy following surgery in those patients. As opposed to younger breast cancer patients, patients with breast cancer over 65 are treated with less aggressive chemotherapy and radiotherapy approaches [3]. As the drugs used in chemotherapy such as cyclophosphamide, doxorubicin, vincristine and prednisone might have side effects such as myelosuppression that increase in severity with age, dosage reductions are indicated in chemotherapy protocols of elderly breast cancer patients. Decreased GFR and Hb levels with advanced age might cause renal failure and cardiovascular complications, which are the most commonly seen complications in elderly patients during treatment $[10,12,13]$. Treatment approaches that contain anthracycline are more preferred in hormone receptor positive breast cancers and in tumors with increased HER2/neu expressions. However, dosage and treatment period should be carefully considered in elderly breast cancer patients due to the risk of anthracycline-related cardiotoxicity [2].

Hormonal therapy in advanced age breast cancer cases is very effective due to increased hormonal receptor positivity. Today, tamoxifen and taromifen are the basic options for this treatment. There are studies that report 2-year tamoxifen usage decreased recurrence by $25 \%$ and mortality by $16 \%$ in post-menauposal breast cancer patients with axillary lymph node involvement. Moreover, a meta-analysis study done by Early Breast Cancer Trials Collaborative Group reported that 5 years of tamoxifen treatment is more effective than 2 years of treatment
[13-15]. The studies that research tamoxifen treatment for 5 or more years suggest that hormonal therapy should be at least continued for 5 years or more [10].

Mortality in advanced age breast cancer patients in post-treatment term cannot be clearly evaluated. However, most of the studies reported that the patients are more likely to die from chronic diseases and related complications than breast cancer $[6,8,9]$.

\section{References}

1. NIH (2016) Surveillance, Epidemology and End Results Program, National Cancer Institute.

2. Sautter-Bihl ML, Souchon R, Gerber B (2011) Adjuvant therapy for women over age 65 with breast cancer. Dtsch Arztebl Int 108: 365-371. [Crossref]

3. Pang A, Ho S, Lee SC (2013) Cancer physicians' attitude towards treatment of the elderly cancer patient in a developed Asian country. BMC Geriatr 13: 35. [Crossref]

4. Roiland RA, Heidrich SM (2011) Symptom clusters and quality of life in older adult breast cancer survivors. Oncol Nurs Forum 38: 672-680. [Crossref]

5. Cappellani A, Di Vita M, Zanghì A, Cavallaro A, Piccolo G, et al. (2013) Prognostic factors in elderly patients with breast cancer. BMC Surg 13 Supp1 2: S2. [Crossref]

6. Bellet M, Alonso C, Ojeda B (1995) Breast cancer in the elderly. Postgrad Med J 71: 658-664. [Crossref]

7. Paap E, Verbeek A, Botterweck A, Doorne-Nagtegaal H, Imhof-Tas M, et al. (2014) Breast Cancer screening halves the risk of breast cancer death: A case referent study. Breast 23: 439-444.

8. Ament SM, Gillissen F, Maessen JM, Dirksen CD, Bell AV, et al. (2014) Sustainability of short stay after breast cancer surgery in early adopter hospitals. Breast 23: 429-434. [Crossref]

9. Docimo G, Limongelli P, Conzo G, Gili S, Bosco A, et al. (2013) Axillary lymphadenectomy for breast cancer in elderly patients and fibrin glue. BMC Surg 13 Suppl 2: S8. [Crossref]

10. Balducci L, Extermann M, Carreca I (2001) Management of breast cancer in the older woman. Cancer Control 8: 431-441. [Crossref]

11. Ahmed M, Abdullah N, Cawthorn S, Usiskin SI, Douek M (2014) Why should breast surgeons use ultrasound. Breast Cancer Res Treat 145: 1-4. [Crossref]

12. Sekine I, Fukuda H, Kunitoh H, Saijo N (1998) Cancer chemotherapy in the elderly Jpn J Clin Oncol 28: 463-473. [Crossref]

13. Markopoulos C, Water W (2012) Older patients with breast cancer: is there bias in the treatment they receive. Ther Adv Med Oncol 4: 321-327

14. Caldeira S, Carvalho EC, Vieira M3 (2014) Between spiritual wellbeing and spiritual distress: possible related factors in elderly patients with cancer. Rev Lat Am Enfermagem 22: 28-34. [Crossref]

15. [No authors listed] (1998) Tamoxifen for early breast cancer: an overview of the randomised trials. Early Breast Cancer Trialists' Collaborative Group. Lancet 351: 1451-1467. [Crossref]

Copyright: (C2016 Ay AA. This is an open-access article distributed under the terms of the Creative Commons Attribution License, which permits unrestricted use, distribution, and reproduction in any medium, provided the original author and source are credited. 